\title{
Oxygen Probe and Sublance Probe Equipped with Oxygen Sensor*
}

\section{Description}

By the ZIRCOMEX oxygen probe, oxygen activity in molten steel and bath temperature can be measured simultaneously.

In conventional methods, the oxygen measured in a frozen sample is the total oxygen, therefore including oxygen as oxide inclusions: by the oxygen probe, however, the oxygen activity directly related to the steelmaking reaction can be rapidly measured. Thanks to this feature, it can be used on line in the steelmaking operation.

Conventionally, the sublance probe has been used for measuring molten steel temperature and carbon content and for extracting samples for analysis. The recently developed CONTEG-Z can be also used to simultaneously measure the oxygen activity dissolved in molten steel.

The following is a description of these two probes.

\section{Structures and Features}

1. Oxygen Probe "ZIRCOMEX"

ZIRCOMEX is composed of a thermocouple for measuring the temperature of molten steel and an oxygen concentration cell for measuring oxygen activity.

The solid electrolyte of the oxygen concentration cell, a tube type with one closed end, is coated with alumina on its outer circumference to ensure stable measurement and quick response. The reference electrode is made of a mixture of $\mathrm{Cr}$ and $\mathrm{Cr}_{2} \mathrm{O}_{3}$.

The tip of the multipaper protective tube is comprised of ceramic fiber of high refractoriness.

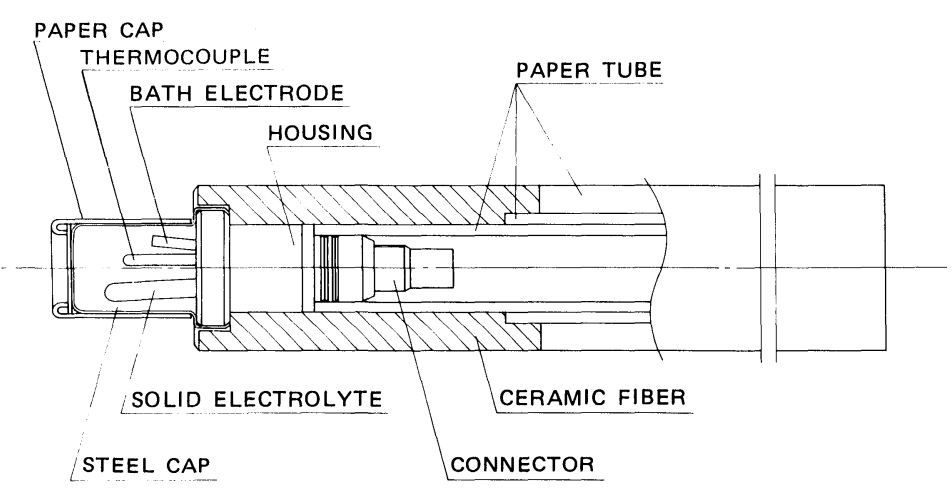

Fig. 1. Oxygen probe "ZIRGOMEX".

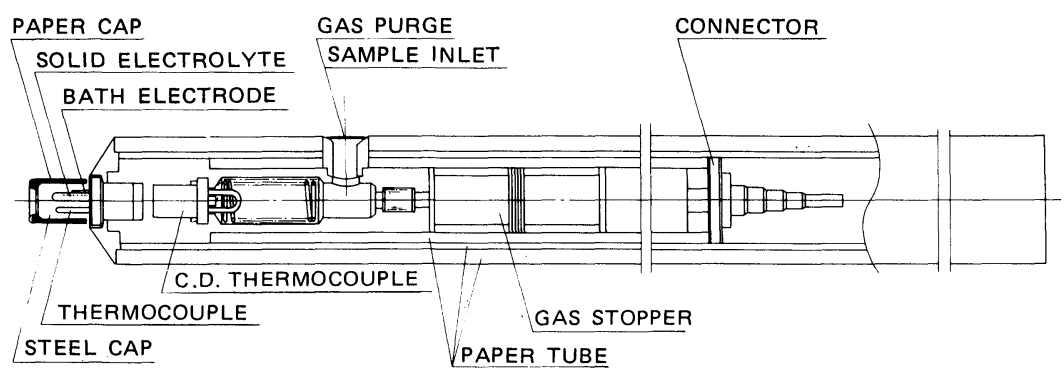

Fig. 2. Sublance probe " CONTEG-Z".

With about $10 \mathrm{sec}$ immersion in molten steel, ZIRCOMEX gives highly accurate measurements of oxygen activity, ranging from slightly less than $1 \mathrm{ppm}$ to a little bit more than $1000 \mathrm{ppm}$.

\section{Sublance Probe with Oxygen Sen- sor "CONTEC-Z"}

CONTEG-Z is composed of an oxygen sensor at the end, for measuring oxygen activity and bath temperature and a thermocouple in the sample chamber for measuring carbon content. Silica sand is employed to the sample chamber as its material to ensure a stable solidifying temperature waveform.

In the CONTEG-Z, gas supplied via. the sublance is purged through the sampling hole.

\section{Applications}

By ZIRCOMEX, the oxygen activity can be rapidly and accurately measured over a wide range. For this reason, it is used in many types of steelmaking equipment, such as converters, electric furnaces, degassing systems and LF furnaces. Since ZIRCOMEX is highly accurate, even in the lower oxygen activity range of less than $10 \mathrm{ppm}$, it is particularly suitable for quantitative estimation of soluble Al.

By CONTEG-Z, temperature, carbon content and oxygen activity of molten steel can be measured simultaneously for the dynamic control of the converters. Phosphorus concentration at blowingout can be estimeted from the oxygen activity measurement.

\footnotetext{
* For further information, write to International Trading Dept., Osaka Sanso Kogyo Ltd., 12-4, 2-chome, Utajima, Nishiyodogawa-ku, Osaka 555. (C) 1985 ISIJ
} 